\title{
CPW-Fed Fractal Slot Antenna for UWB Application
}

\author{
Hou Zhang, Hai-Yang Xu, Bo Tian, and Xian-Feng Zeng \\ Radar Engineering Department, Missile Institute of Air Force Engineering University, Shaanxi Province Sanyuan 713800, China
}

Correspondence should be addressed to Hai-Yang Xu, xuhaiyang.8888@163.com

Received 15 December 2011; Accepted 20 February 2012

Academic Editor: Ahmed A. Kishk

Copyright (C) 2012 Hou Zhang et al. This is an open access article distributed under the Creative Commons Attribution License, which permits unrestricted use, distribution, and reproduction in any medium, provided the original work is properly cited.

\begin{abstract}
A novel printed ultrawideband (UWB) CPW-fed Koch fractal slot antenna is proposed. The UWB bandwidth is largely enhanced by the three-iteration Koch fractal slot whose extrusive angle is 900 instead of 600 to obtain better convoluted shape and selfsimilarity. The $-10 \mathrm{~dB}$ impedance bandwidth is $3400 \mathrm{MHz}(1270-4670 \mathrm{MHz})$ or about $114 \%$ in comparison with $1290 \mathrm{MHz}$ $(1620-2910 \mathrm{MHz})$ or about $57 \%$ of the referenced square slot antenna. Details of the proposed antenna design and performance are presented and discussed.
\end{abstract}

\section{Introduction}

Owing to the progress in wireless communication systems and the increase in their applications, the ultrawideband (UWB) antenna has become a key component in developing the UWB technique [1]. Conventional antennas are designed to radiate in a relatively narrow range of frequencies. As opposed to traditional narrowband antennas, the UWB antennas can transmit and receive electromagnetic waves in a wide range. The UWB antennas are used to transmit the pulses with minimum distortion in the shape of the pulses. What is more, the demand for portable, low profile, and compact wireless systems has increased research interests in miniature antennas [2]. As an important member of the UWB family, the slot antenna has the merits of wideband, low cost, light weight, easy fabrication and so on [35]. It can be easily integrated with microwave integrated circuits. What is more, they have the merits of low radiation loss, less dispersion too. The coplanar-waveguide- (CPW-) fed printed slot antennas have the simplest structure of a single metallic layer [3-7]. It can be easily integrated with monolithic microwave-integrated circuits. Some attempts have been made to enhance the bandwidth among various slot antennas, including the use of taper CPW [3], loaded strips [4], inset L-strip tuning stub [5], and U-shaped tunning stub [6]. Reference [7] used a widened tuning stub to enhance the bandwidth of the square slot antenna to $60 \%$ bandwidth.
The term fractal, which means broken or irregular fragments, was originally coined by Mandelbrot to describe a family of complex shapes that possess an inherent selfsimilarity in their geometrical structure. Fractal antennas, due to the property of self-similarity and the ability of filling the space, have the self-loaded characteristic to allow for smaller, multiband and broadband antenna design [8-14]. So they can enhance the bandwidth without any additional matching element.

In this paper, a promising bandwidth-enhancement technique is applied in the CPW-fed slot antenna in [15]. The modified Koch fractal is applied in the slot of the proposed antenna. The slot is achieved by three Koch iterations. And then through adjusting the gap between the tuning stub and the ground plane, the impedance bandwidth can enhance largely.

\section{Antenna Design and Performance}

The geometry of the proposed antenna is shown in Figure 1. The antenna is printed on the FR-4 substrate with the thickness of $h=1.6 \mathrm{~mm}$ and relative permittivity of $\varepsilon_{r}=4.6$. The ground is chosen to be square, whose side length is $G=72 \mathrm{~mm}$. The antenna is fed by a $50 \Omega \mathrm{CPW}$ feed line, which has a metal strip of width $w_{f}=6.37 \mathrm{~mm}$ and a gap of distance $g=0.5 \mathrm{~mm}$. A widened tuning stub of length $L_{3}=22.5 \mathrm{~mm}$ and width $w=36 \mathrm{~mm}$ is connected to the 


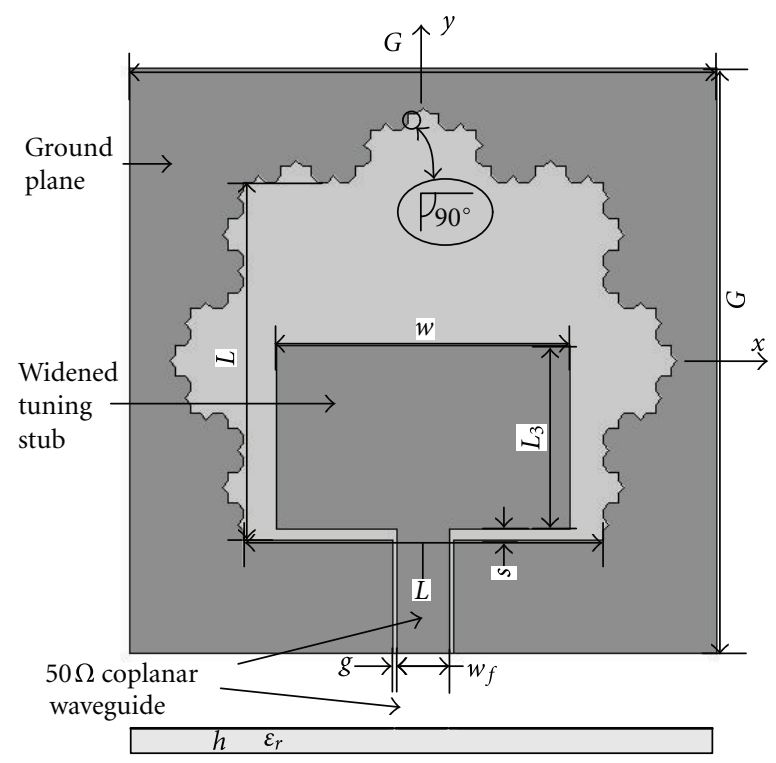

FIGURE 1: Geometry of the proposed antenna.
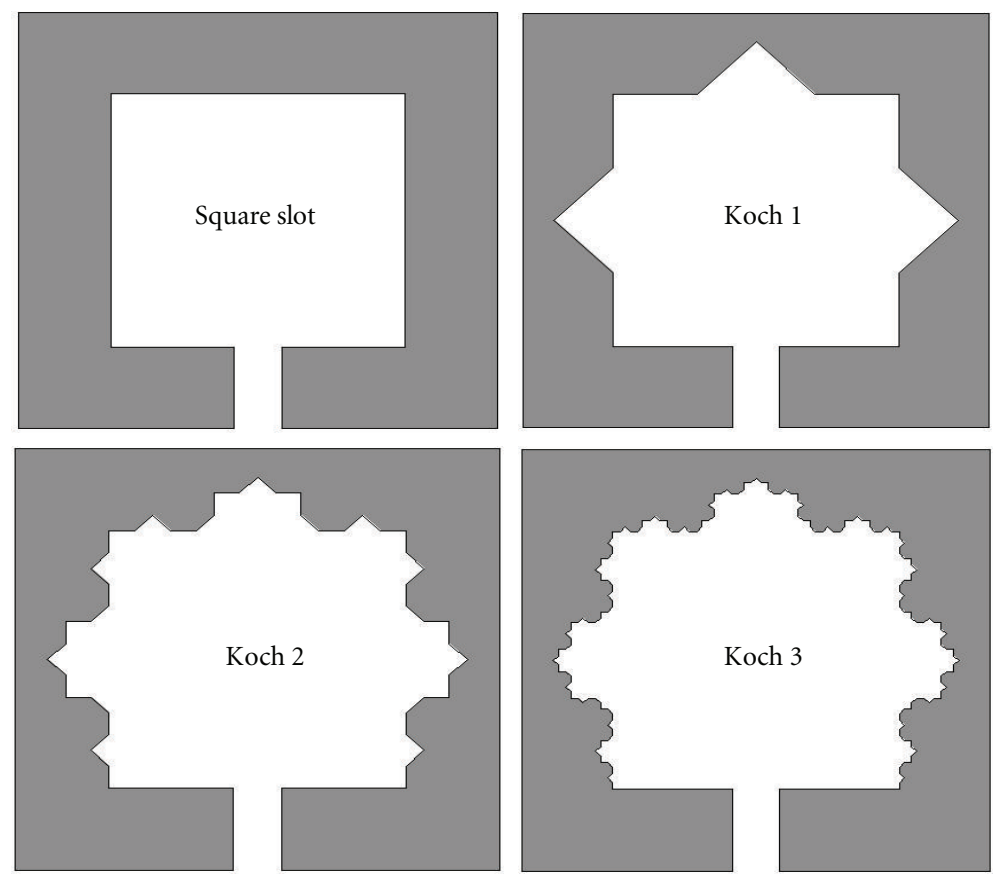

Figure 2: Geometries of the square slot and the Koch island for different iterations.

end of the CPW feed line. Unlike the tuning stub in [12], that of the proposed antenna is symmetrical with respect to the feed line and printed in the same layer with the metal ground. This design can obtain more symmetrical radiation patterns, especially in the high-frequency section. The spacing between the tuning stub and edge of the ground plane is $S=1.4 \mathrm{~mm}$. The Koch fractal slot is achieved by 3 iterations based on the square slot of $L=44 \mathrm{~mm}$.

Figure 2 gives the geometry of square slot and three modified Koch slots with different iterations. Unlike the Koch fractal forms in $[13,14]$, the extrusive angle of fractal is $90^{\circ}$ instead of $60^{\circ}$ so as to obtain better convoluted shape in the slot and better self-similarity in the corners. Three sides of the square slot are replaced by the $90^{\circ}$-angle Koch islands. Higher iterations of the modified Koch curves are constructed by subtracting smaller and smaller right-angled isosceles triangles from the former structure, as shown in Koch $1-3$ of Figure 2.

At higher iteration $k$, the area of the slot increases. Let $A_{k}$ be the area of the slot at Koch $k$ (let the area of the square slot 


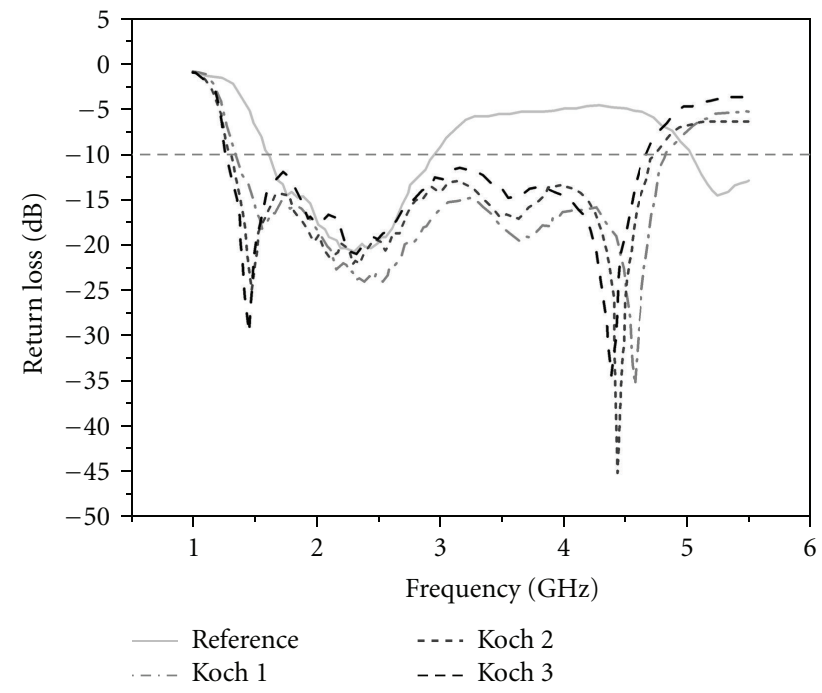

Figure 3: Comparison of the measured return loss.

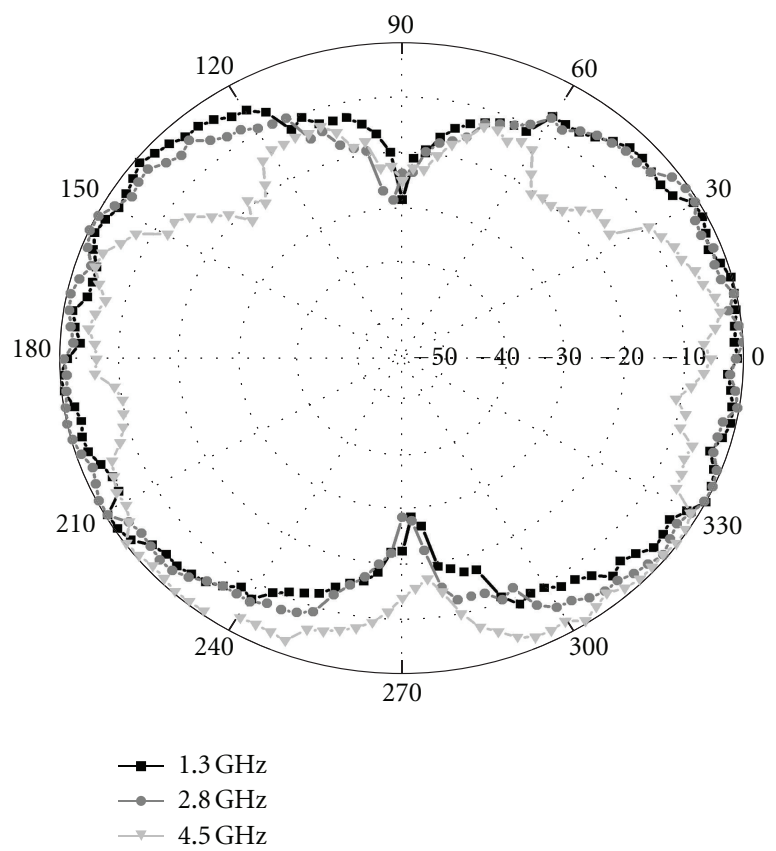

(a)

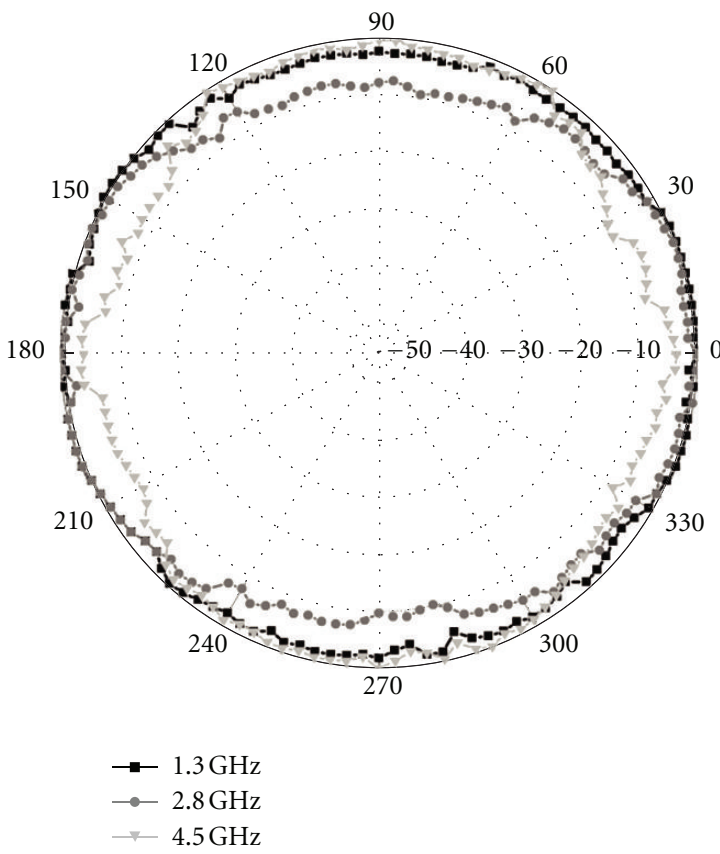

(b)

Figure 4: Measured copolarized far-field radiation patterns: (a) E pane, (b) H plane.

be $\left.A_{0}\right)$, then the area of the next iteration can be computed as

$$
A_{k+1}=A_{k}+\frac{3}{8}\left(\frac{2}{3+2 \sqrt{2}}\right)^{k+1} * a^{2},
$$

where $a$ is the side of the initial square slot that has an area $A_{0}=a^{2}$.

The overall perimeter for Koch $k$ is given by

$$
l_{k}=\frac{3}{2} \cdot(2-\sqrt{2})^{k} a+a
$$

The perimeter increases by $l_{k}-4 a$, which means the resonance frequency reduction can be achieved. In other words, with the assigned resonance frequency, the volume of the antenna is reduced with the higher iterations.

Figure 3 shows return loss of reference and modified Koch slot antennas for different iterations. As shown in Figure 3, the measured $-10 \mathrm{~dB}$ impedance bandwidth of the Koch fractal antenna is $3400 \mathrm{MHz}(1270-4670 \mathrm{MHz})$ or about $114 \%$, while the reference one without the fractal iterations is $1290 \mathrm{MHz}(1620-2910 \mathrm{MHz})$ or about $57 \%$. The 


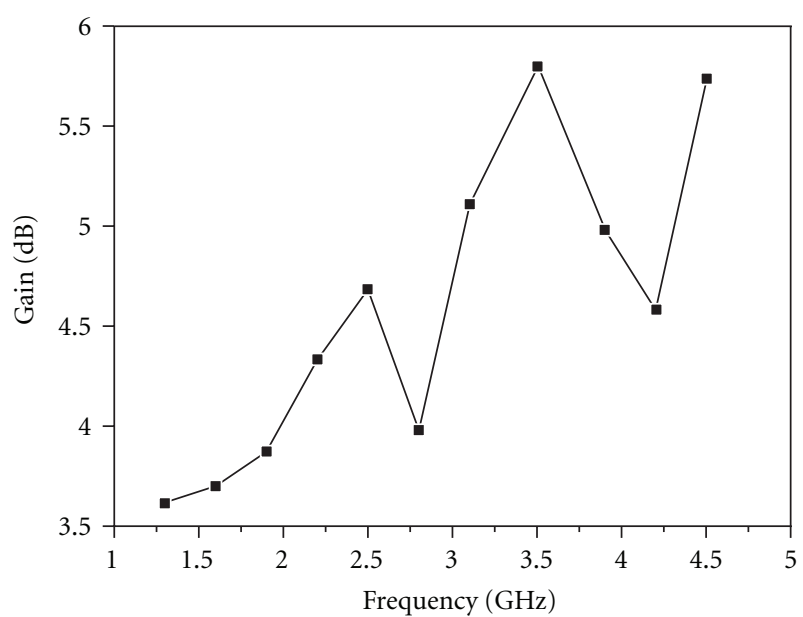

FIGURE 5: Gain against frequency.

Koch fractal expands the bandwidth to be about 2 times of the reference antenna with a square slot.

Figure 4 is the measured copolarized far-field radiation patterns of novel antenna at $\mathrm{E}$ and $\mathrm{H}$ planes at different frequencies. The radiation patterns keep relatively symmetrical and stable at both planes in the whole operating frequency band.

Figure 5 is the gain of the fractal slot antenna. The maximum and minimum values are 5.7 and $3.6 \mathrm{~dB}$, respectively, resulting in the maximum gain variation of $2.1 \mathrm{~dB}$ over the entire UWB frequency band.

\section{Conclusion}

A novel CPW-fed Koch fractal slot antenna has been proposed and investigated. The application of the Koch fractal slot enhances the impedance bandwidth obviously. This design is a breakthrough in expanding the bandwidth of the slot antenna and can be directly applied to UWB communications. This fractal technique can also be expected to apply other antennas with square or rectangular slots to enhance the impedance bandwidth.

\section{References}

[1] S. S. Zhong and X. L. Liang, "Progress in ultra-wideband planar antennas," Journal of Shanghai University, vol. 11, no. 2, pp. 95-101, 2007.

[2] H. T. Nguyen, S. Noghanian, and L. Shafai, "Microstrip patch miniaturization by slots loading," in Proceedings of the IEEE Antennas and Propagation Society International Symposium and USNC/URSI Meeting, pp. 215-218, Washington, DC, USA, 2005.

[3] C. Y. Huang and D. Y. Lin, "CPW-fed bow-tie slot antenna for ultra-wideband communications," Electronics Letters, vol. 42, no. 19, pp. 1073-1074, 2006.

[4] J. Y. Chiou, J. Y. Sze, and K. L. Wong, "A broad-band CPWfed strip-loaded square slot antenna," IEEE Transactions on Antennas and Propagation, vol. 51, no. 4, pp. 719-721, 2003.
[5] B. Purahong, P. Jearpradikul, T. Archevapanich, N. Anantrasirichai, and O. Sangaroon, "CPW-fed slot antenna with inset U-strip tuning stub for wideband," in Proceedings of the International Conference on Control, Automation and Systems, pp. 1781-1784, Seoul, Korea, October 2008.

[6] R. Chair, A. A. Kishk, K. F. Lee, C. E. Smith, and D. Kajfez, "Microstrip line and CPW fed ultra wideband slot antennas with U-shaped tuning stub and reflector," Progress in Electromagnetics Research, vol. 56, pp. 163-182, 2006.

[7] B. Mirzapour and H. R. Hassani, "Size reduction and bandwidth enhancement of snowflake fractal antenna," IET Microwaves, Antennas and Propagation, vol. 2, no. 2, pp. 180-187, 2008.

[8] H.-Y. Xu, H. Zhang, G.-Y. Li, and Q.-B. Xu, "An ultrawideband fractal slot antenna with low backscattering cross section," Microwave and Technology Letters, vol. 53, no. 5, pp. 1150-1154, 2011.

[9] B. Mirzapour and H. R. Hassani, "Size reduction and bandwidth enhancement of snowflake fractal antenna," IET Microwaves, Antennas and Propagation, vol. 2, no. 2, pp. 180-187, 2008.

[10] R. Kumar and P. Malathi, "Design of dual wide band CPW-fed fractal antenna," in Proceedings of the International Conference on Emerging Trends in Electronic and Photonic Devices and Systems, ELECTRO '09, pp. 289-292, December 2009.

[11] Y. B. Thakare and Rajkumar, "Design of fractal patch antenna for size and radar cross-section reduction," IET Microwaves, Antennas and Propagation, vol. 4, no. 2, pp. 175-181, 2010.

[12] H. Y. Xu, H. Zhang, G. Y. Li, Q. B. Xu, and K. Lu, "An ultrawideband fractal slot antenna with low backscattering cross section," Microwave and Optical Technology Letters, vol. 53, pp. 1150-1154, 2011.

[13] D. D. Krishna, M. Gopikrishna, C. K. Anandan, P. Mohanan, and K. Vasudevan, "CPW-fed Koch fractal slot antenna for WLAN/WiMAX applications," IEEE Antennas and Wireless Propagation Letters, vol. 7, Article ID 2000814, pp. 389-392, 2008.

[14] D. D. Krishna, M. Gopikrishna, C. K. Aanandan, P. Mohanan, and K. Vasudevan, "Compact wideband Koch fractal printed slot antenna," IET Microwaves, Antennas and Propagation, vol. 3, no. 5, pp. 782-789, 2009.

[15] H. D. Chen, "Broadband CPW-fed square slot antennas with a widened tuning stub," IEEE Transactions on Antennas and Propagation, vol. 51, no. 8, pp. 1982-1986, 2003. 

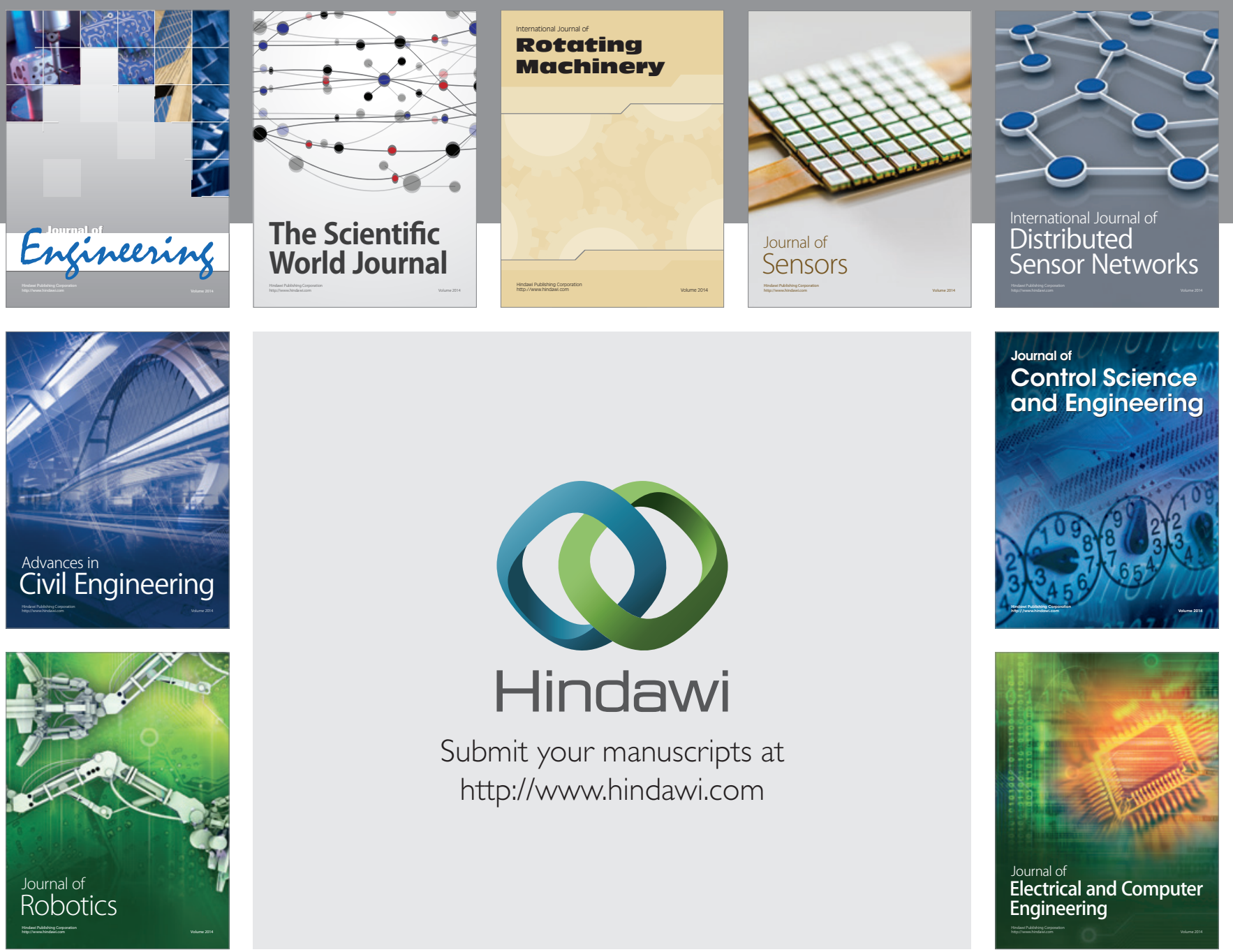

Submit your manuscripts at

http://www.hindawi.com
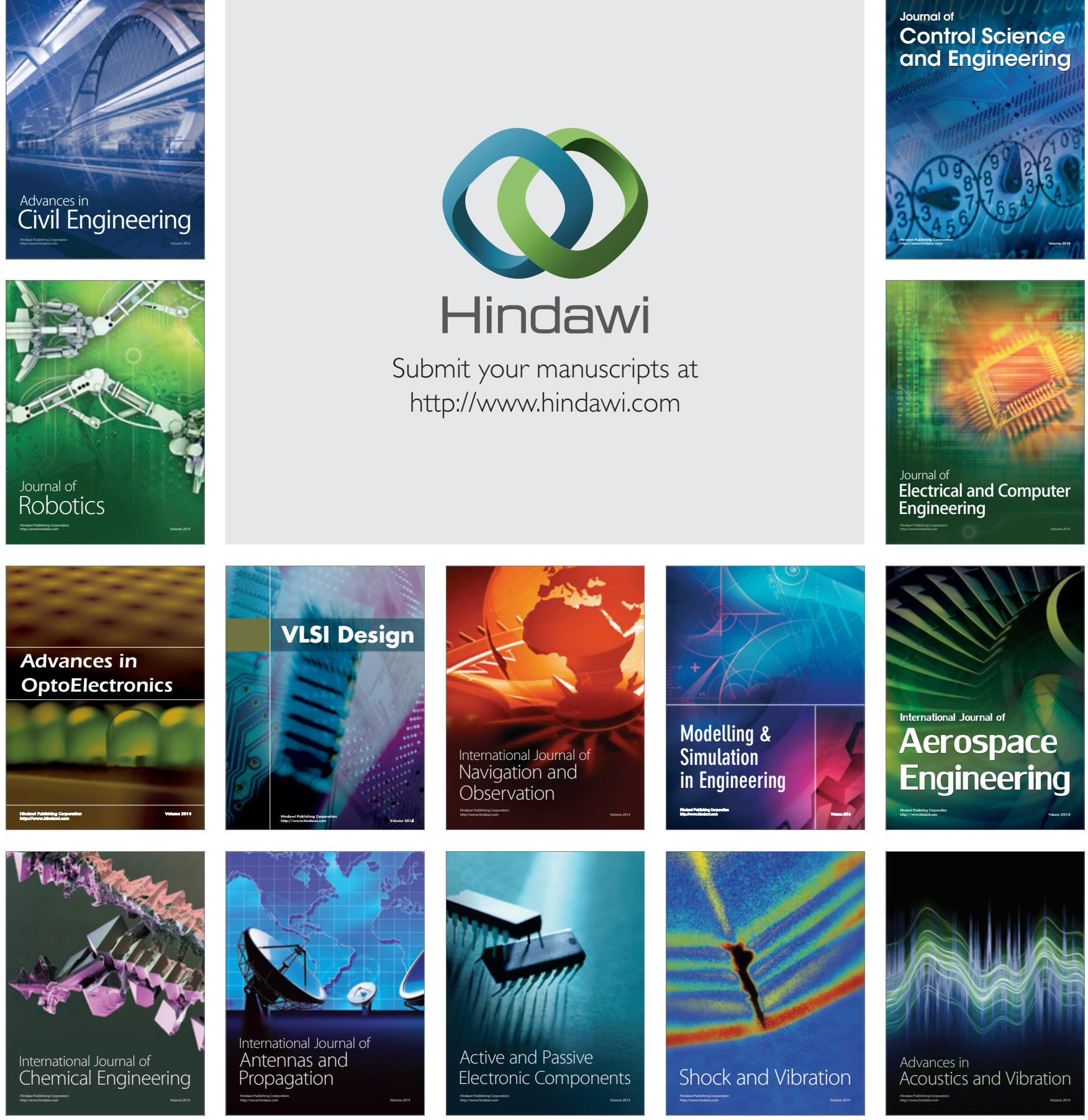